Clinics in Haematology, Vol. 8, No. 2. Cellular Dynamics of Haemopoiesis

Edited by L. G. Lajtha. Pp. viii +310 , illustrated. W. B.

Saunders, London, Philadelphia and Toronto, 1979. £8.25. Medical research often advances in great surges. We seem to be past such a surge in immunology. On the other hand,we are clearly on the upward slope of activity in relation to haemopoietic stem cells and hence this volume of Clinics in Haematology entitled Cellular Dynamics of Haemopoiesis is very timely.

The book is directed more to the scientist than the physician and will be of most use to research workers in this exciting area. The field is still dominated by problems of methodology and this is discussed in relation to the different cell lines.

Sections deal with pluripotent stem cells, genetic anaemias in mice, granulocyte-monocyte precursors as assessed in semi-agar culture, regulation of granulopoiesis, erythroid stem cells in relation to human disease, erythroid and granulocytic kinetics, megakaryocytopoiesis, lymphopoiesis, surface markers and cell sorters, haemopoietic regulation and leukaemic cells. Some sections may not be easy to read other than by those engaged in the field; and those who, like the reviewer, look for an idiot's guide to stem cells and their regulation, had better start with a simpler description of events before graduating to this more advanced volume. A Colour Atlas of Gynaecological Surgery. Vol. 3: Operations
for Malignant Disease

By David H. Lees and Albert Singer. Pp. 352, illustrated. Wolfe Medical Publications, London, 1979. $£ 33$.

This volume, like its predecessors, provides a detailed stepby-step photographic account of operations, the colour photographs being accompanied by a concise written commentary. The colour photographs are of a high quality with anatomical details highlighted by the use of indicators and line diagrams. The visual resolution achieved by the photographs of intra-pelvic operations is perhaps not quite as high as that in the case of vulval operations, but could probably not be improved on except by the use of stereoscopic photography.

There are separate chapters covering the surgical treatment of carcinoma of the vulva; cervical carcinoma; uterine carcinoma; ovarian carcinoma and recurrent pelvic malignancy; as well as a chapter reviewing the radiation therapy of gynaecological cancer. The chapters on carcinoma of the vulva and cervix have useful introductory sections on the applied anatomy of the region, and also describe the role of lymphography in the pre-operative work-up of these conditions. It is therefore a little surprising that the authors' criteria for performing a radical vulvectomy as distinct from a radical vulvectomy with pelvic lymphadenectomy, seem to be based on slightly arbitrary clinical criteria without apparently taking the extent of lymphatic spread into consideration. However, this is only a minor criticism of a beautifully produced book which trainee specialists in gynaecology will find extremely useful to prepare them for and to supplement what they will learn from their teachers in the operating theatre.

\section{The Control of Chronic Pain}

By SAmpson Lipton. Current Topics in Anaesthesia Series. Edited by S. A. Feldman and C. F. Scurr, No. 2. Pp. $x+134$, illustrated. Edward Arnold, London, 1979. £7.95.

Advances in anaesthesia, as in so many other fields in medicine, are proceeding at such a rate that it is difficult even for the specialist to select and retrieve information from this enormously enlarging pool of knowledge. Moreover, in an acute speciality such as anaesthesia, failure to keep abreast of such advances can seriously affect the standard of patient care. This volume is the second in a new series entitled Current Topics in Anaesthesia under the general editorship of Stanley Feldman and Cyril Scurr which aims to provide a solution to this problem. We are promised a selection of topics where there is a particular need for a clear digest and considered evaluation of current information. Already the first volume on intravenous anaesthetic agents has appeared and other titles will include neuroanaesthesia and medical problems and the anaesthetist.

Dr Lipton is particularly well qualified as author of this book since he is Director of the Centre for Pain Relief at the Walton Hospital, Liverpool, and is well known for his contributions to this subject. In this short volume he outlines the physiology and pharmacology of pain and discusses the organization of pain relief clinics. He stresses, by the way, the importance of including the word 'relief' in the title of such a Unit. He then considers specific chronic painful problemsheadaches, rheumatic conditions and cancer. Treatment includes wide choice of modalities and Dr Lipton's descriptions range over the use of drugs, electric neuromodulation, acupuncture, hypnosis, percutaneous cordotomy, pituitary injection of alcohol and a wide variety of nerve blocks. The chapters are brief so that the whole book can be read in an evening, but they do give an invaluable over-view of the subject. Certainly the technical details and diagrams given for some of the more elaborate treatments would be insufficient to enable a tiro to carry them out without further help. However, there are extensive references for additional reading and the interested anaesthetist would be well advised to see the expert at work.

It is surprising that more is not being done to try to relieve the enormous burden which chronic incurable pain presents to patients. As the author states in his preface "it is amazing to realise that only in recent years has the idea arisen of treating pain as an entity when the underlying medical condition cannot be cured'. Certainly anaesthetists have an important part to play in what is rapidly becoming an important new speciality and this volume serves as an excellent introduction to an important subject.

\section{Data Interpretation Questions for the MRCP}

By Richard Ashford and Patrick Venables. Pp. 200,

illustrated. Churchill Livingstone, Edinburgh, London and

New York, 1979. £2.95 (paperback).

This little book provides practice in laboratory data interpretation for the general Membership candidate. There is a good balance of the various disciplines with electrocardiograms, lung function, haematology and strictly chemical pathology data represented. The answers are short and specific and therein lies the weakness of this book. Although the authors in their introduction state it is not their aim to 'be a textbook' the reader receives little guidance when he is 'wrong' nor do the authors provide reassurance that their answers are indeed correct by referencing them. Nearly all the practice question books suffer from this fault. This criticism not withstanding, this book is a worthwhile addition to the exam candidate's 'bank'.

\section{Epidemiology for the Uninitiated}

By G. Rose and D. J. P. Barker. Pp. 59. Articles published by the British Medical Journal, British Medical Association, London, 1979. $£ 2.50$ (paperback).

Epidemiology, the study of disease in relation to populations, has rightly become of increasing importance. Although excellent publications on the subject already exist, many have been deterred by the sophistry of their arguments and the complexity of the statistical techniques which they imply. This book seeks to remedy the situation by addressing itself to the 'uninitiated'. It is based on articles by two distinguished epidemiologists which were commissioned by the British Medical Journal and are now presented in book form. It 
describes with great clarity and deceptive simplicity the underlying concept of the subject and its techniques for the collection and interpretation of data in population studies. Practical advice is given on how to plan and conduct surveys, how to assess disease rates, prognosis and aetiology in such a way that valid conclusions may be drawn. The use of screening and the evaluation of definitive measures are considered. Many of the propositions in the text are illustrated by simple examples taken from the literature which make no demands on the mathematical abilities of the reader. It was surely unconscious humour which led the authors to criticize a paper on hang-gliding accidents because of problems with the 'floating numerator'. Stephen Lock, the Editor of the B.M.J., in his foreword rightly states that 'Few things are more dispiriting for a medical editor than having to reject a paper based on a good idea but with irremediable flaws in the methods used'. An appreciation of the principles enunciated in this book are surely a prerequisite for the conduct of many aspects of medical research. It deserves to be read by all postgraduates involved in academic work and particularly by those with an interest in community medicine.

\section{Geriatrics. Guidelines in Medicine-Volume 1}

By A. N. Exton-Smith and P. W. Overstall. Pp. 344. MTP Press, Lancaster, 1979. £9.95.

The authors have produced in the space of 300 odd pages a most readable account of the special features of medical problems as seen in the older patient. Chapters are carefully balanced to emphasize common problems and clarity is aided by short lists and tables. For those who wish to pursue a subject in greater depth, there is a small number of carefully selected modern references (up to 1978). It is always difficult for a reviewer to refrain from the habit of medical 'fault finding' but it is unfortunate that the ECG purporting to show digoxin intoxication shows ST and T changes which are non-suggestive of ischaemia.

The book is suitable for undergraduates and for those dealing with geriatric problems either in hospital or in general practice. It is highly recommended.

\section{Human Growth. Volume 3. Neurobiology and Nutrition}

Edited by F. Falkner AND J. M. TANner, Pp. xviii +606 illustrated. Baillière Tindall, London, 1979. $£ 24.75$.

This is the final volume of a series of three devoted to aspects of human growth. It comprises two main sections dealing with neurobiology and nutrition respectively. The first section contains a series of chapters concerned with the anatomical and functional growth of the brain and nervous system and the factors which affect their orderly development. The neuronal control of breathing, sleep organization and sexual differentiation of the brain are discussed together with sections on the early neurological and behavioural development. The chapter on critical periods in relation to behavioural development contains much that will fascinate the clinical paediatrician with regard to the problems of neonatal separation and adoption.

The second section of this volume is concerned with nutrition and its relation to growth and development. The topics on the nutritional aspects of growth in infancy, protein-energy malnutrition, obesity and population status receive extensive treatment. The important problem of nutrition in relation to the development of the brain and its functions are fully considered.

The final chapter gives a fascinating but concise account of the history of growth studies from Buffon in the 18th century to the present day. The publication of this volume completes a series which is destined to become a standard work. It is commended to paediatricians, neonatologists and specialists in the growth and development of children as an outstanding contribution to their growth subjects and a valuable source of reference.

\section{Local Analgesia}

By C. Jolly. 2nd edition. Pp. vii +144 , illustrated. H. Kঙํํ Lewis, London, 1979. £5.00.

Variety is one of the pleasures of anaesthetic practice, foo many methods are usually available — and apparently equall $\overline{\bar{p}}$. effective-for the solution of the same clinical problem. Ou्फ current inability to show any overall differences betwee尺 patients anaesthetized by totally dissimilar techniques 驾 certainly a reflection of present-day ignorance. A danger of this situation is that, because in general one cannot show that approach $\mathbf{A}$ is any better than approach $\mathbf{B}$ to an anaesthetic problem, it is not difficult to make a strong but usuall $\vec{w}$ illogical case for approach $A, B$ or $Z$ being universally the best method and the only one that should be used. Unt recently the use of local anaesthetic methods was a prime example of this form of polarization. Schools of thought existed that claimed that local analgesia was the method above all of providing ideal conditions for the surgeon and patient or, alternatively, that local techniques had no place् in modern anaesthetic practice. In the last few years memberis of both camps have probably come to realize that truth lies somewhere between these extremes.

Where does the second edition of this small book, coming 17 years after it first appeared, fit into the present spectrum $\$$ It is not intended for those who want to know when it is best to use a local technique, for it discusses virtually no alterna 3 tives. Nor is it aimed at those who want to learn how to perform various blocks, or useful as a reference book, for the number of local blocks described is limited and the book contains a mere 19 line drawings (the lifeblood of all standighro books on local techniques). It would seem then that this borolo has little to offer anyone, but this is not quite true. Dr Jally has a fund of clinical wisdom and sound experience derised from his great experience of local analgesia, and hidden awas throughout the book are small gems-concerned not wit/ how to put a needle near a nerve or how much of what drug to inject where, but how to handle a patient, how to deal witip or avoid complications. This would, in fact, have been a mucl better book if Dr Jolly had eschewed all the descriptive sections (which are covered very adequately in numerous other texts) and devoted himself to the management of surgical procedures using local anaesthetic techniques.

\section{The Medical Report and Testimony}

By Gerald H. Pearce. Foreword by the Right Honourable

Mr Justice Melford Stevenson. Pp. 104, 1979. £6.50.

This book sets out to explain an important and often. neglected area of co-operation between the medical and legal professions. The author, a consultant orthopaedic surgeon has drawn on his long experience of reporting in personal injury cases to explain the essentials of preparing medical reports and to give both professions a mutual understanding of each other's points of view and problems은. Any doctor or lawyer would benefit from reading the book whether an experienced or novice practitioner.

The author deals with one running sore between the pro fessions whereby solicitors delay payment of a doctor's repore fee until an action is settled. The author rightly condemnsw that approach which aggrieves many a doctor.

There is a useful chapter on the approximate periods of total and partial disability resulting from more commone injuries. The glossaries of medical and legal terms are the least successful parts of the book. No doubt because of limited space the author had to be excessively selective buto the space taken up would be much better used by referringo the reader to legal and medical encyclopaedias. Futures 